\title{
Regionalização bioclimática do Rio Grande do Sul: um estudo do conforto térmico humano em escala climática regional e sub-regional
}

\author{
Bioclimatic regionalization of Rio Grande do Sul: a study of human thermal comfort in regional and \\ sub-regional climatic scale
}

João Paulo Assis Goboํㄹ Emerson Galvani ${ }^{1}$, Cassio Arthur Wollmann²

${ }^{1}$ Universidade de São Paulo, USP, SP, Brasil.

${ }^{2}$ Universidade Federal de Santa Maria, UFSM, RS, Brasil.

\section{Resumo}

A presente pesquisa buscou avaliar o conforto térmico para o Rio Grande do Sul, a partir de um zoneamento do conforto térmico humano visando o estabelecimento de uma regionalização climática para o Estado. Para tanto foram analisados dados meteorológicos referentes à temperatura do ar, umidade relativa do ar e velocidade do vento para um período de 30 anos (1981-2010), estabelecendo-se, também, a definição de três anos-padrão para uma análise mais pontual. Os dados coletados foram submetidos ao cálculo dos índices de conforto térmico de Temperatura Efetiva com vento (TEv) e Temperatura Resultante (TE), os quais foram espacializados e geraram o zoneamento do conforto térmico para a área de estudo. Os resultados apontaram que as regiões climáticas mais adequa das ao conforto térmico humano são influenciadas pela dinâmica atmosférica regional, bem como pelos atributos físicos destas áreas no decorrer das quatro estações do ano.

Palavras-chave: Regiões Climáticas; Zoneamento; Dinâmica Atmosférica.

\begin{abstract}
This study concerns in to evaluate the thermal comfort for the Rio Grande do Sul, from a zoning of human thermal comfort for the establishment of a climate regionalization for the State. So, meteorological data such as air temperature, relative humidity and wind speed were collected for a period of 30 years (1981-2010) and they were analyzed, also settling the definition of three pattern-years to a more precise analysis. The data collected were subjected to the calculation of thermal comfort indices of Effective Temperature with wind (VTE) and Resultant Temperature (TE), which were spatially and generated zoning of thermal comfort for the study area. The results showed climate regions more suitable for human thermal comfort influenced by regional atmospheric dynamics, as well as the physical attributes of these areas during the four seasons.
\end{abstract}

Keywords: Climate Regions; Zoning; Atmospheric Dynamics. 


\section{INTRODUÇÃO}

O zoneamento bioclimático permite identificar áreas geográficas com condições climáticas similares, onde o planejamento, mediante aplicações de estratégias de acondicionamento natural, pode promover conforto térmico aos seus usuários, reduzir a demanda de energia para calefação ou refrigeração e evitar impactos prejudiciais a saúde humana (EVANS, 2003).

Para Ometto (1981, p. 405), o zoneamento é “... a escolha dos locais mais indicados para as diversas culturas, a fim de obter-se uma maior rentabilidade do capital investido", este conceito pode ser adaptado para o zoneamento bioclimático humano e assim congregando métodos aplicados nas ciências agronômicas com métodos de zoneamento bioclimático aplicados pela arquitetura e engenharia.

Em 1981, a Argentina desenvolveu um zoneamento bioclimático sob a denominação de "Clasificación Bioambiental de la República Argentina" Norma IRAM 11.603. O trabalho delimitou seis zonas e dez sub-zonas bioambientais e estabeleceu que as exigências para com os padrões construtivos fossem de caráter indicativo e não obrigatórias, sendo que quando se trata de moradias de interesse social o rigor da norma é obrigatoriamente aplicado no requerimento de isolamento térmico.

Tratando-se do zoneamento do Conforto Térmico Humano, atenta-se para o trabalho de Zoneamento Climático da República do México, que mapeou as zonas de desconforto por calor, conforto e desconforto por frio no território mexicano de acordo com os meses do ano (MORILLÓN, et al. 2004).

Changnon, et al., (2000) alerta que temperaturas muito elevadas e muito reduzidas, podem aumentar o risco de morbidade e mortalidade, principalmente em ambientes onde a faixa de conforto térmico não apresenta boa abrangência climática, caracterizando menor tolerância da população a estas adversidades biometeorológicas.

Assim, tendo como base para este estudo o estado do Rio Grande do Sul, buscou-se avaliar as condições de conforto térmico nas escalas regional e subregional no estado, segundo as médias mensais e sazonais de temperatura do ar, da umidade relativa do ar e velocidade do vento, com a finalidade de se estabelecer uma regionalização climática para o Rio Grande do Sul com base no zoneamento do conforto térmico.

\section{CARACTERIZAÇÃO DA ÁREA DE ESTUDO}

A área de estudo selecionada para esta pesquisa corresponde ao Estado do Rio Grande do Sul, localizado no extremo sul do Brasil, entre as coordenadas

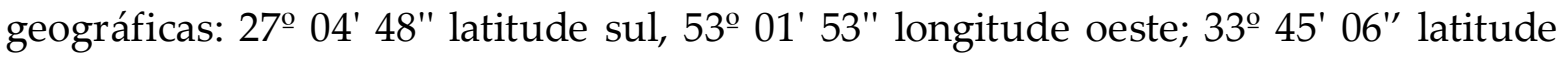




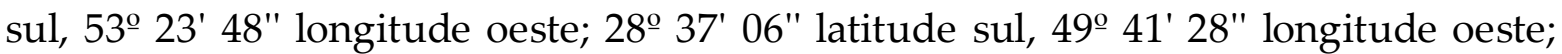
$30^{\circ} 11^{\prime} 18^{\prime \prime}$ latitude sul, 57웅' 38' 36" longitude oeste (IBGE, 2014).

No que se refere às características naturais, o Rio Grande do Sul atualmente está dividido em cindo unidade geomorfológicas em relação à compartimentação geomorfológica do Estado, que é fortemente condicionada pela geologia regional, são elas: Planalto Meridional, Planície Costeira, Escudo Sul-Rio-grandense, Depressão Central e Cuestas do Haedo (Figura 1A) (SEMA/RS, 2010).

As altitudes máximas ultrapassam a cota de 1200 metros acima do nível do mar principalmente no limite com o Estado de Santa Catarina, no Planalto da Bacia do Paraná, e constitui-se num grande controle climático, principalmente na variação das precipitações e da temperatura do ar (Figura 1B) (SEMA/RS, 2010).
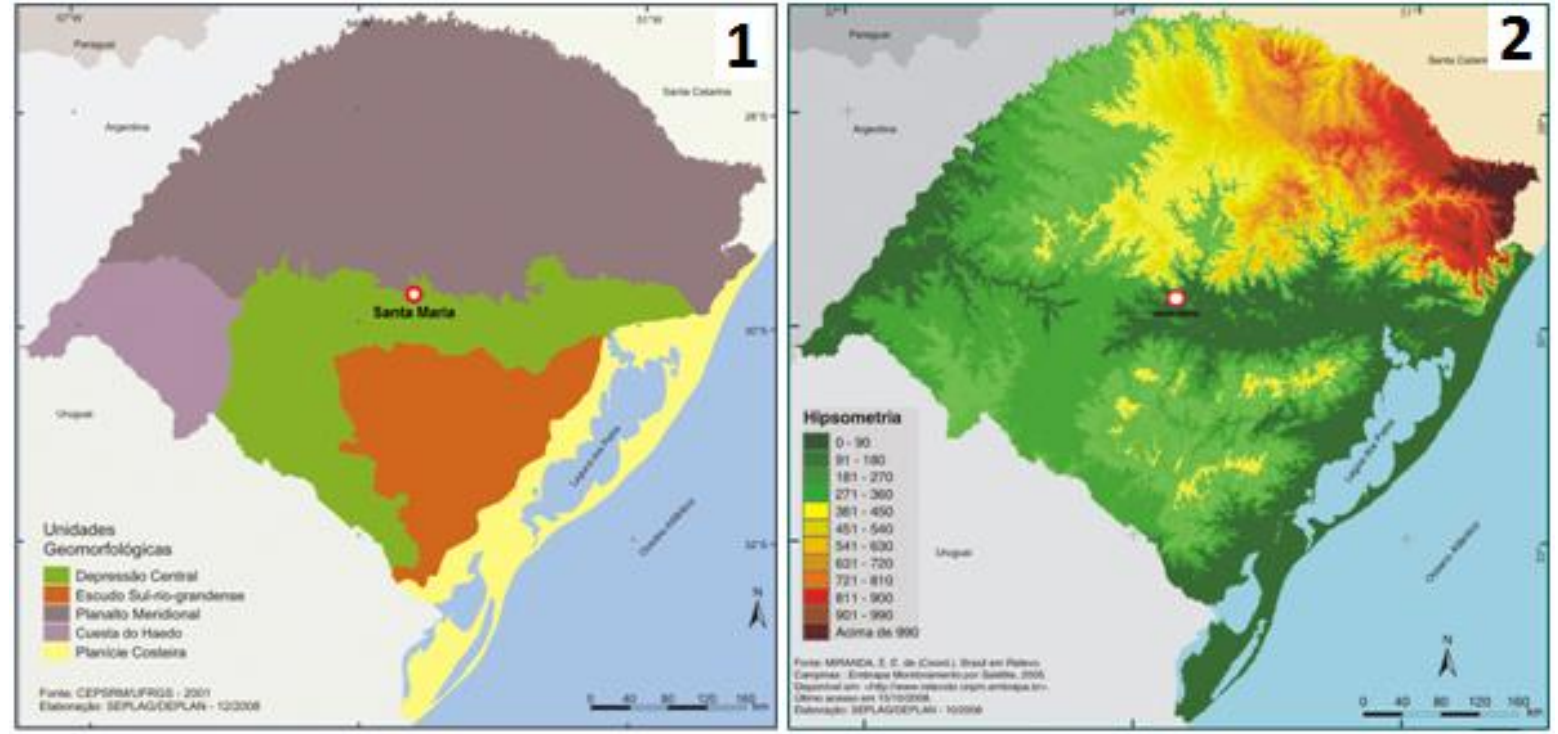

Figura 1: Mapa das unidades Geomorfológicas do Rio Grande do Sul. Figura 2: Mapa hipsométrico do Rio Grande do Sul. Fonte: Atlas Socioeconômico do Rio Grande do Sul (2010).

\section{MATERIAIS E MÉTODOS}

Para a realização desta pesquisa foram utilizados dados meteorológicos referentes à temperatura do ar, à umidade relativa do ar e à velocidade do vento, para uma série temporal de 30 anos, correspondentes aos anos compreendidos entre 1981 e 2010.

Os dados utilizados foram coletados de 23 estações meteorológicas, sendo estas de responsabilidade do Instituto Nacional de Meteorologia (INMET).

Após a obtenção das médias mensais e sazonais de temperatura do ar, de umidade relativa do ar e de velocidade do vento, os dados foram submetidos aos cálculos do Índice de Temperatura Efetiva com Vento (TEv) (SUPING et al., 1992) e Índice de Temperatura Resultante (TR) (MISSENARD, 1948).

Calcularam-se os índices TEv para os meses de outono e de inverno de cada ano da série de 30 anos e para cada uma das 23 estações meteorológicas, a partir dos 
dados das médias sazonais de temperatura do ar, de umidade relativa do ar e de velocidade do vento, como mostra a equação 1 :

$$
\text { TEv }=37-\frac{(37-T)}{\left[0,68-0,0014 R H+\frac{1}{1,76+1 / 4 v^{0,75}}\right]}-0,29 T\left(1-\frac{R H}{100}\right) \quad \text { Equação 1: }
$$

Onde: T é a temperatura do ar em ${ }^{\circ} \mathrm{C}$; $\mathrm{RH}$ é a umidade relativa em \%; v é a velocidade do vento em $\mathrm{m} / \mathrm{s}$ (medida a 10 metros de altura); TEv é a temperatura efetiva em função do vento em ${ }^{\circ} \mathrm{C}$.

Para os meses de primavera e verão calculou-se o índice de Temperatura Resultante (MISSENARD, 1948) para cada ano da série de 30 anos, para cada uma das 23 estações meteorológicas com uso da seguinte fórmula expressa na equação 2:

$$
\text { TR }=\text { Ts }-0,4(T s-10)(1-\text { UR / 100) } \quad \text { Equação 2: }
$$

onde: TR é a temperatura resultante $\left({ }^{\circ} \mathrm{C}\right)$; Ts é a temperatura do ar (bulbo seco) ( $\left.{ }^{\circ} \mathrm{C}\right)$; UR é a umidade relativa do ar (\%).

Em virtude de o Rio Grande do Sul não possuir uma classificação das zonas de conforto térmico adequadas aos padrões climáticos do Estado, a presente pesquisa utilizou-se da Classificação Térmica desenvolvida por Maia e Gonçalves (2002) para espaços urbanos abertos na cidade de São Paulo, com base nas condições de conforto térmico estabelecido por Fanger (1972).

Maia e Gonçalves (2002) propuseram uma comparação entre diferentes índices de conforto térmico e o índice TEv. A partir daí, com uma distribuição da frequência dos tipos de tempo durante o ano de 1999 em São Paulo, estabeleceram as zonas de conforto propostas a seguir, no Quadro 1.

Quadro 1 - Classes de conforto térmico adaptadas à pesquisa

\begin{tabular}{ccc}
\hline Tev $\left(\mathbf{C}^{\mathbf{o}}\right)$ & Sensação Térmica & Grau de Estresse Fisiológico \\
\hline$<13$ & Muito Frio & Extremo Estresse ao Frio \\
\hline $13-16$ & Frio & Tiritar \\
\hline $16-19$ & Frio Moderado & Ligeiro Resfriamento do Corpo \\
\hline $19-22$ & Ligeiramente Frio & Vasoconstrição \\
\hline $22-25$ & Confortável & Neutralidade Térmica \\
\hline $25-28$ & Ligeiramente Quente & Ligeiro Suor e Vasodilatação \\
\hline $28-31$ & Quente Moderado & Suando \\
\hline $31-34$ & Quente & Suor em Profusão \\
\hline$>34$ & Muito Quente & Falha na Termorregulação
\end{tabular}

Fonte: Maia e Gonçalves (2002). Org. do Autor.

Na etapa seguinte atribuíram-se as classes Interpretativas para a Sensação Térmica, desenvolvidas por Maia e Gonçalves (2002) e fez-se a edição final dos mapas, no software ARCGIS 3.2. 
Para realizar o zoneamento final do conforto térmico para o Rio Grande do Sul, foi realizada a seleção de três anos-padrão (2002, mais chuvoso; 2004, mais seco; 2007, habitual) dentre os 30 anos da série histórica, a partir da metodologia adotada no emprego da análise rítmica, técnica proposta por Monteiro (1969, 1971, 2000), a qual se torna subsídio metodológico e técnico na investigação geográfica dos tipos de tempo, em sua sucessão habitual e extrema, condição que configura o ritmo climático (MOURA; ZANELLA, 2012).

Para a regionalização do conforto térmico no Rio Grande do Sul, adotou-se uma técnica de "overlay" (sobreposição) dos dados obtidos em função de suas respectivas classes, ou seja, os valores resultantes do zoneamento final foram distribuídos de acordo com o intervalo de classes utilizado para definição das faixas de conforto.

Assim, o menor valor representado no mapa de zoneamento final ficou sendo o valor mínimo da classe estabelecida, correspondendo à faixa de sensação térmica de Muito Frio, enquanto o valor máximo obtido no zoneamento final passou a corresponder à faixa de sensação térmica de Muito Quente, sendo os demais valores distribuídos de acordo com as demais faixas de sensação térmica, dando origem ao mapa de regionalização climática do Rio Grande do Sul, com base no zoneamento do conforto térmico humano.

Adotou-se esse procedimento em face dos resultados observados na análise da dinâmica atmosférica regional, os quais evidenciaram a possibilidade de ocorrência de extremos de desconforto térmico; tanto tendentes para o frio como para o calor, mostraram os extremos de temperatura máxima e mínima nessas estações, comparando-se os dois episódios (verão e inverno).

Para a conclusão desta análise, foram calculadas as porcentagem de ocorrências de cada faixa de conforto térmico classificada no território do Rio Grande do Sul e elaborou-se um mapa síntese da regionalização climática da área de estudo (mapa da macrorregionalização climática), o qual compreende os valores obtidos na regionalização climática do Rio Grande do Sul, com base no zoneamento final, agrupados em apenas três classes: "Desconforto por Frio" (com todos os valores de TEv e TR abaixo do limite inferior da zona de conforto), "Confortável" (com valores de TEv e TR dentro da zona de conforto) e "Desconforto por Calor" (compreendendo todos os valores de TEv e TR acima do limite superior à zona de conforto).

\section{ANÁLISE DOS RESULTADOS}

\section{Zoneamento do conforto térmico para os invernos da série de 30 anos}

No zoneamento do conforto térmico para os meses de inverno da série de 30 anos, assim como no zoneamento do outono, foram calculados os valores de TEv, sendo que estes se apresentaram ainda mais baixos, classificando todo o território 
do Estado na faixa de sensação térmica de "Muito Frio", como pode ser verificado no mapa da Figura 2A.

O zoneamento para os meses de inverno, no Rio Grande do Sul, apresentouse muito mais homogêneo e generalizado do que os zoneamentos para as demais estações do ano, mais uma vez em função de os dados médios de TEv dificultarem um zoneamento nessa escala.

Nesse zoneamento para os meses de inverno da série de 30 anos, todas as regiões do Rio Grande do Sul apresentam médias de TEv abaixo de $13^{\circ} \mathrm{C}$, o que as coloca na faixa de sensação térmica de "Muito Frio" e permite a possibilidade de inferir que o conforto térmico no Estado para uma situação média de inverno é determinado muito mais pela dinâmica atmosférica (maior atuação de sistemas extratropicais), que mantém as temperaturas baixas durante esse período do ano.

Sendo assim, fatores de controle do clima, tais como a proximidade ou distância dos corpos d'água e a altitude não são responsáveis, pelo menos em análise média, pela determinação das situações de conforto e desconforto térmico no Rio Grande do Sul.

\section{Zoneamento do conforto térmico para os outonos da série de 30 anos}

$\mathrm{O}$ zoneamento do conforto térmico para os meses de outono da série de 30 anos é apresentado no mapa da Figura $2 \mathrm{~B}$ é similar ao da série dos 30 anos. No entanto, o mapa de zoneamento do outono apresenta o Estado dividido em apenas duas faixas de sensação térmica, as de "Muito Frio" e "Frio".

Analisando-se o mapa, é possível observar que a maior parcela do Rio Grande do Sul se encontra classificada na faixa de sensação térmica de "Frio", sendo as regiões representadas pela Depressão Periférica Sul Rio-Grandense, Litoral médio do Estado, extremo oeste e região noroeste (vale do rio Uruguai) assim como pela parte oeste do Planalto Meridional da Bacia do Paraná. Tais regiões caracterizam-se por apresentar temperaturas médias, nessa estação do ano, em tordo de $13^{\circ} \mathrm{C}$ a $16^{\circ} \mathrm{C}$.

Em contrapartida, há duas regiões do Estado inseridas na faixa de sensação térmica de "Muito Frio", sendo elas a Serra Gaúcha e o extremo sul do Estado, com temperaturas médias, nessa estação do ano, abaixo de $13^{\circ} \mathrm{C}$.

Há nesse caso uma evidente influência do vento na determinação do zoneamento do conforto térmico para os outonos da série de 30 anos, pois as regiões definidas na faixa de sensação térmica de "Muito Frio" são aquelas de maior incidência de vento nessa época do ano (SARTORI, 2003).

No caso das demais regiões do Rio Grande do Sul inseridas na faixa de sensação térmica de "Frio", verifica-se um altitude que varia entre $0 \mathrm{~m}$ e $600 \mathrm{~m}$, o que pode demonstrar a não influência da altitude na determinação de conforto térmico nessa época do ano, sendo este fortemente influenciado pelo vento.

Chama-se a atenção para o fato de que, diferentemente do zoneamento do conforto térmico para o verão e para a primavera, o zoneamento para o outono e inverno utilizou-se apenas do Índice de Temperatura Efetiva com Vento (TEv), o 
qual atribui valores de velocidade do vento em sua equação, enquanto o Índice de Temperatura Resultante (TR), utilizado no zoneamento do verão e da primavera, não faz uso da influência do vento. Entretanto, lembra-se que esse método foi utilizado em função da baixa ocorrência de vento nos meses de primavera/verão na área de estudo.

\section{Do Zoneamento do Conforto Térmico Para a Série de 30 Anos}

De acordo com o mapa da Figura 2C, o Rio Grande do Sul não apresenta nenhuma zona de conforto (neutralidade) para a série de 30 anos. A maior parte da área de estudo está inserida na faixa de sensação térmica de "Frio", homogeneizando praticamente todo o interior do estado.

A região da serra gaúcha, localizada no nordeste do Estado, e a região do extremo sul encontram-se inseridas na classe de "Muito Frio", o que em princípio pode estar relacionado à influência do vento. Este, nos meses de outono e inverno, é bastante intenso e constante nessas regiões, seja em função da altitude, no caso da serra, como da proximidade com o oceano e também da latitude, no caso do extremo sul do Estado (SARTORI, 2003).

No entanto, na região noroeste do Estado - vale do rio Uruguai e fronteira com a Argentina - há a situação de desconforto classificada na faixa de sensação térmica de "Frio Moderado", sendo este resultado possivelmente relacionado à influência da continentalidade e ao fato de as altitudes dessa região serem relativamente baixas (200 m ANM) em relação aos pontos mais elevados do Estado (1400 m ANM).

A homogeneidade das classes apresentadas no mapa deve-se ao fato de esta etapa da pesquisa ter sido trabalhada apenas com as médias anuais da série de 30 anos, fazendo com que os verdadeiros resultados das zonas de conforto tenham sido sub-valorizados.

Essa homogeneidade do zoneamento do conforto térmico em escala regional, atribuída aos valores médios dos atributos climáticos, pode ser observada também nos trabalhos de Morillón (2004) e no zoneamento climático da República do México, de Navarro (2007).

Oliveira et. al. (2006) já haviam comprovado tal homogeneidade no zoneamento bioclimático ao tratar de dados médios. No entanto, vale salientar que, apesar de a escala de análise climática também ser regional no trabalho desse autor, a presente pesquisa, ao tratar de escala espacial, analisa apenas o Estado do Rio Grande do Sul.

No zoneamento anual da série de 30 anos, não ocorreram áreas com faixa de sensação térmica "Ligeiramente Frio", "Confortável", "Ligeiramente Quente", "Quente Moderado", "Quente" e "Muito Quente", conforme as classes apresentadas anteriormente na metodologia.

A seguir, verifica-se na Tabela 1 a frequência de TEv e TR para o zoneamento da série de 30 anos, no território do Rio Grande do Sul, de acordo com a classe de sensação térmica. 
Tabela 1 - Porcentagem de ocorrências das faixas de sensação térmica classificadas no zoneamento para a série de 30 anos.

\begin{tabular}{ccc}
\hline Faixas & Sensação Térmica & $\begin{array}{c}\text { Porcentagem de ocorrências no } \\
\text { território do RS (\%) }\end{array}$ \\
\hline$<13$ & Muito Frio & 17,4 \\
\hline $13-16$ & Frio & 52,2 \\
\hline $16-19$ & Frio Moderado & 26,1 \\
\hline $19-22$ & Ligeiramente Frio & 0 \\
\hline $22-25$ & Confortável & 0 \\
\hline $25-28$ & Ligeiramente Quente & 0 \\
\hline $28-31$ & Quente Moderado & 0 \\
\hline $31-34$ & Quente & 0 \\
\hline$>34$ & Muito Quente & 0 \\
\hline
\end{tabular}

Org. do Autor.

É possível observar na tabela 1 que 17,4\% das ocorrências de TEv e TR no verão da área de estudo estão classificados na zona de "Muito Frio", enquanto 52,2\% do total das ocorrências de TEv e TR encontram-se classificados na zona de "Frio". Os outros 26,1\% das ocorrências de TEv e TR estão classificados na zona de desconforto por "Frio Moderado".

\section{Zoneamento do Conforto Térmico Para as Primaveras da Série de 30 Anos}

O mapa da Figura 2D apresenta também, o zoneamento do conforto térmico para os meses de primavera da série de 30 anos, sendo que nesse zoneamento, diferentemente do zoneamento do inverno, é possível verificar três faixas de sensação térmica, sendo estas as de "Ligeiramente Frio", Frio Moderado" e "Frio".

A maior parcela do Estado encontra-se inserida na faixa de sensação térmica de "Frio Moderado", a qual se caracteriza por valores médios de TR entre $16^{\circ} \mathrm{C}$ e $19^{\circ} \mathrm{C}$.

Inserida na faixa de sensação térmica de "Ligeiramente Frio" está parte do noroeste do Estado, incluindo a montante do vale do rio Uruguai. Nessa região, os valores médios de TR oscilam entre $19^{\circ} \mathrm{C}$ e $22^{\circ} \mathrm{C}$.

A região do Estado classificada na faixa de sensação térmica de "Frio" foi parte da Serra Gaúcha, sendo esta restrita às regiões mais elevadas. Nessa faixa de zoneamento, o valor médio de TR para a época do ano em foco oscila em torno de $13^{\circ} \mathrm{C}$ a $16^{\circ} \mathrm{C}$.

Pode-se observar, no caso do zoneamento do conforto térmico para as primaveras da série de 30 anos, que há uma maior relação entre altitude e 
continentalidade influenciando a determinação das faixas de sensação térmica no Rio Grande do Sul, em função de que o vento não vem a ser um elemento influente nesse período do ano no estado e, portanto, não está incluso na equação do Índice de Temperatura Resultante (TR).

\section{Zoneamento do conforto térmico para os verões da série de 30 anos}

No que se refere ao zoneamento dos dados de TR para os verões da série de 30 anos, verificou-se, a partir do mapa da Figura 2E, que o Estado se encontra dividido em três faixas de sensação térmica, sendo estas a de "Frio Moderado", "Ligeiramente Frio" e "Confortável".

É possível observar que grande parte da área de estudo se insere na faixa de sensação térmica "Confortável", sendo as regiões definidas pela Depressão Periférica Sul Rio-Grandense, parte do Litoral, a região do vale do rio Uruguai (noroeste) e parte da Campanha Gaúcha (extremo oeste).

Sobre essa condição pode-se novamente inferir o fator de controle climático exercido pelo relevo, com altitudes baixas, em torno de $0 \mathrm{~m}$ a $250 \mathrm{~m}$ e a continentalidade no caso das áreas classificadas que se encontram mais ao interior do continente.

Inseridas na faixa de desconforto térmico "Ligeiramente Frio", encontra-se parte do Planalto Meridional da Bacia do Paraná e do Litoral Norte bem como toda a metade sul do estado, com temperaturas médias oscilando entre $19^{\circ} \mathrm{C}$ e $22^{\circ} \mathrm{C}$ para essa estação do ano. A única região do Rio Grande do Sul que apresenta valores de TR na faixa de sensação térmica de "Frio Moderado", com temperaturas médias entre $16^{\circ} \mathrm{C}$ e $19^{\circ} \mathrm{C}$, é a região da Serra Gaúcha, onde as altitudes são mais elevadas.

É necessário salientar que para as condições de verão bem como para as de primavera, o índice de conforto térmico utilizado foi o Índice de Temperatura Resultante (TR), o qual não dispõe da influência do vento na sua equação; portanto, diferentemente do mapa de zoneamento médio da série de 30 anos, no mapa do zoneamento para os verões da série os dois principais fatores que influenciam o controle das zonas de sensação térmica no Estado são a latitude e a altitude.

\section{Zoneamento Final e Regionalização Climática do Rio Grande do Sul}

$\mathrm{O}$ zoneamento final do conforto térmico humano para o Estado, tal como descrito na metodologia desta pesquisa, deu origem ao mapa da Figura 2. Este apresenta seis zonas distintas, do ponto de vista do conforto térmico humano, no estado do Rio Grande do Sul. São elas:

\section{$\checkmark \quad$ Zona Ia}

Representada pela região da serra do nordeste, com parte leste do Planalto da Bacia do Paraná. Caracterizada por conforto térmico humano classificado na faixa de sensação térmica de "Muito Frio", com índice TEv e TR médio menor que $13^{\circ} \mathrm{C}$.

\section{Zona Ib}


Abrange a maior parte da metade sul do Estado, ocupando a parte sul do escudo sul-rio-grandense e da região da Campanha, na divisa com o Uruguai. Assim como a zona "Ia", caracteriza-se por conforto térmico humano classificado na faixa de sensação térmica de "Muito Frio", com índice TEv e TR médio menor que $13^{\circ} \mathrm{C}$

\section{$\checkmark \quad$ Zona II}

Representa a zona de maior abrangência no território do Rio Grande do Sul, estendendo-se desde o litoral a leste até a tríplice fronteira entre Brasil, Uruguai e Argentina, no extremo oeste. Também se prolonga para o norte, até a divisa com Santa Catarina, e ocupa áreas do planalto, da depressão periférica, do litoral e da campanha gaúcha. Caracteriza-se por ser uma zona de conforto térmico humano classificado na faixa de sensação térmica de "Frio", com índice TEv e TR médio oscilando entre $13^{\circ} \mathrm{C}$ e $16^{\circ} \mathrm{C}$.

\section{$\checkmark \quad$ Zona IIIa}

A zona em questão compreende uma estreita faixa que se estende do oeste do Estado até o norte, ocupando áreas do planalto da bacia do Paraná e que compreendem também o vale do rio Uruguai. Caracteriza-se por apresentar índice TEv e TR médios entre $16^{\circ} \mathrm{C}$ e $19^{\circ} \mathrm{C}$, o que a classifica na faixa de sensação térmica de "Frio Moderado". 


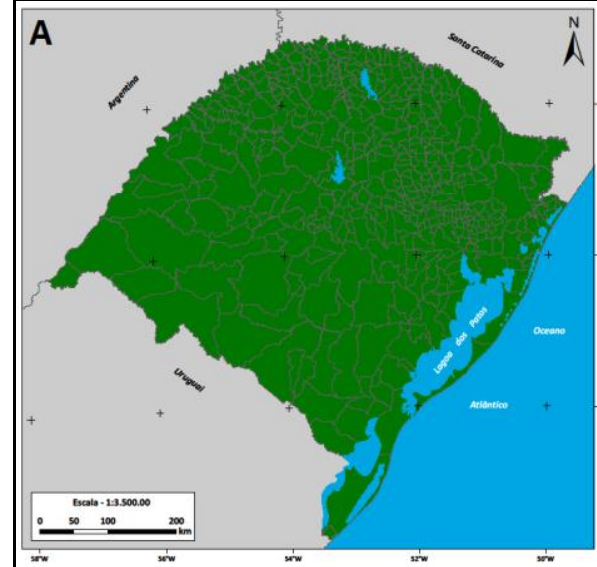

Invernos 30 anos

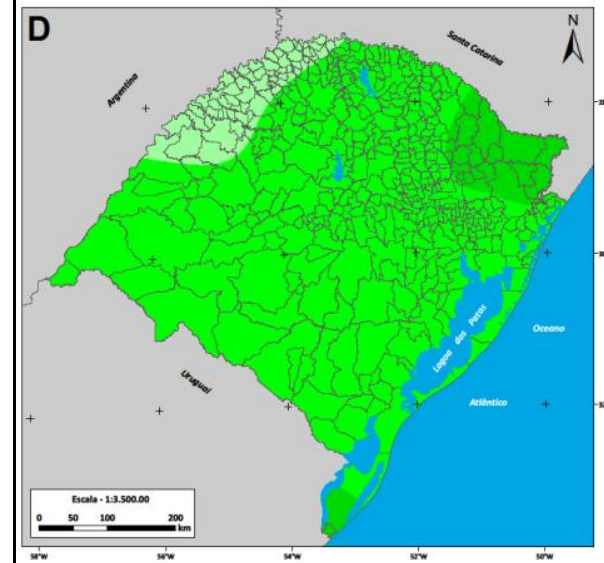

Primaveras 30 anos

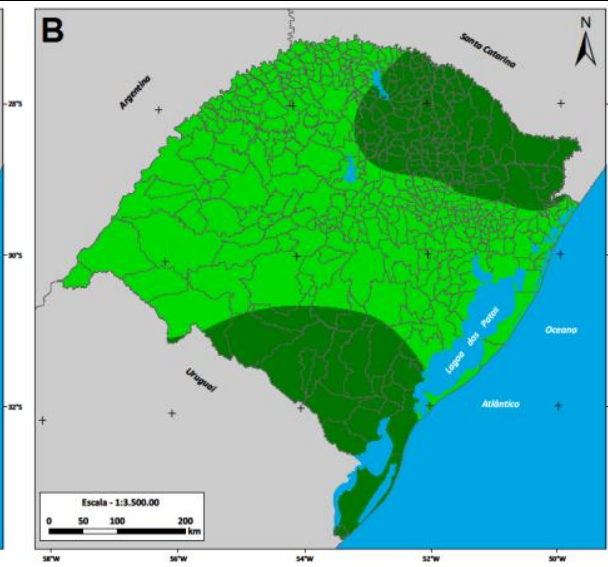

Outonos 30 anos

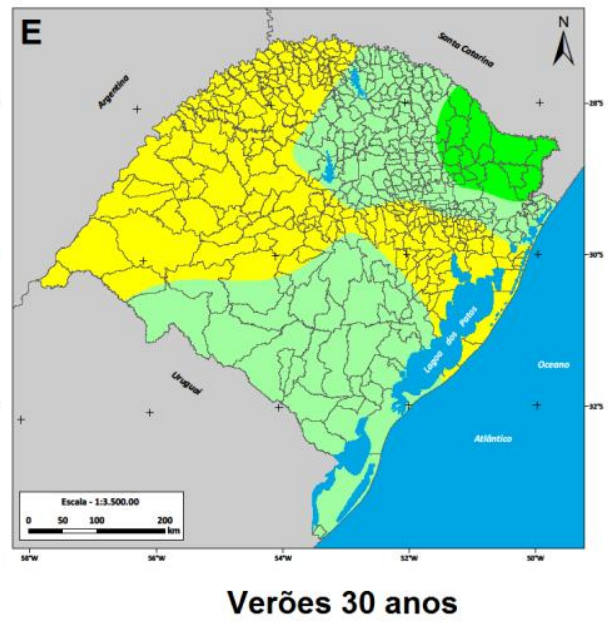

Verões 30 anos

Zoneamento do Conforto Térmico Humano

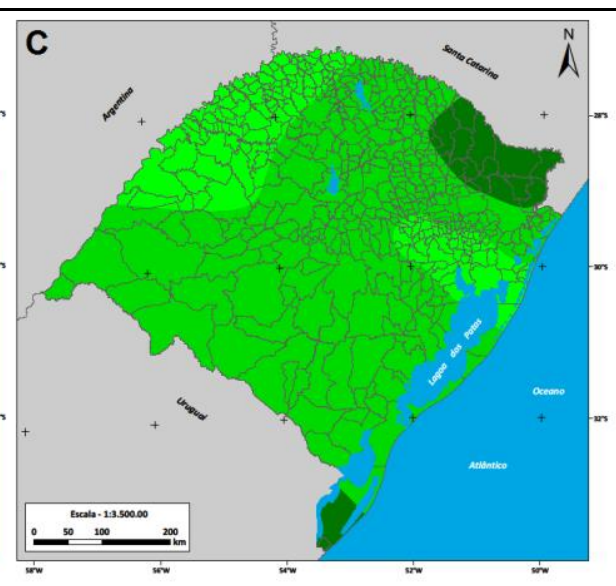

Média dos 30 anos

Legenda:

\begin{tabular}{|l|}
\hline$<13$ \\
$13-16$ \\
$16-19$ \\
$19-22$ \\
$22-25$ \\
$25-28$ \\
$28-31$ \\
$31-34$ \\
$>34$
\end{tabular}

Muito frio

Frio

Frio moderado

Ligeiramente frio

Confortável

Ligeiramente quente

Quente moderado

Quente

Muito quente

Reservatórios e dricos médio sazonal para os 30 anos da série de dados

Figura 2: Mapas do Zoneamento do Conforto Térmico Sazonal e médio da série histórica de 30 anos.

Org. do Autor. 


\section{$\checkmark \quad$ Zona IIIb}

Assim como a zona "IIIa", apresenta índice TEv e TR médios entre $16^{\circ} \mathrm{C}$ e $19^{\circ} \mathrm{C}$, classificando-se na faixa de sensação térmica de "Frio Moderado", porém ocupando uma pequena parte da depressão periférica sul-rio-grandense, no entorno da Região Metropolitana de Porto Alegre, e uma pequena parte do litoral.

\section{$\checkmark \quad$ Zona IV}

Localizada no noroeste do Rio Grande do Sul, ocupando uma faixa próxima ao vale do rio Uruguai pertencente ao planalto da bacia do Paraná, a zona IV é a que apresenta valores mais próximos à faixa de conforto térmico humano adequada, encaixando-se na faixa de sensação térmica de "Ligeiramente Frio" com índice TEv e TR médios entre $19^{\circ} \mathrm{C}$ e $22^{\circ} \mathrm{C}$.

No entanto, ao se observar o zoneamento final do conforto térmico humano para o Rio Grande do Sul, nota-se que essas zonas encontradas não condizem com a real situação do conforto térmico no estado, levando-se em consideração a análise da dinâmica atmosférica em que se observou o clima do Estado de uma maneira dinâmica, em escala diária estudadas por Sartori (1993 e 2003).

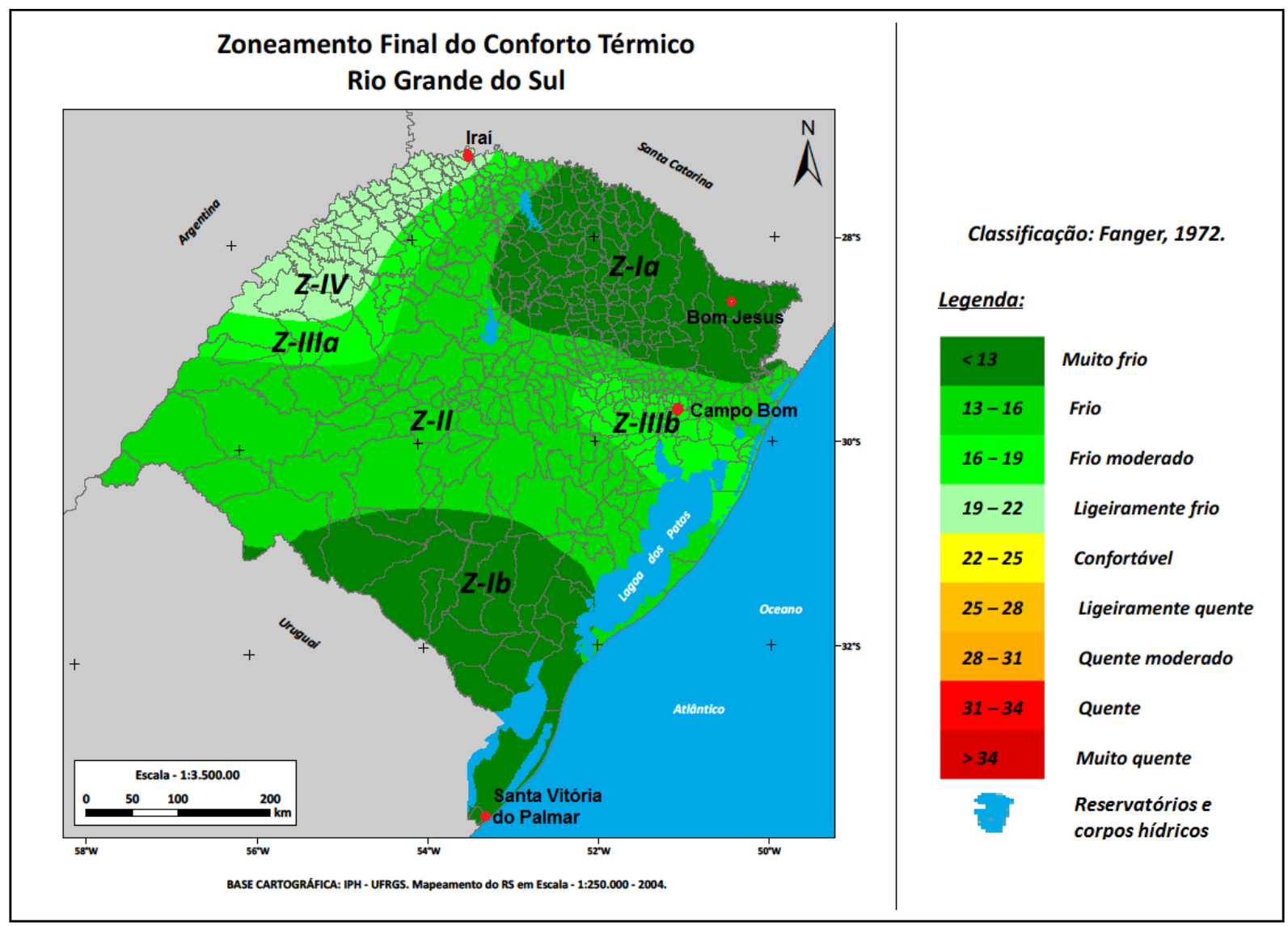

Figura 3: Mapa do Zoneamento do Conforto Térmico para o Rio Grande do Sul. Org. do Autor.

Sendo assim, optou-se por uma análise ainda mais sucinta do clima do Rio Grande do sul, a ponto de se regionalizar seu conforto térmico humano, e, para tal, selecionou-se uma estação meteorológica representativa das duas zonas "mais frias" encontradas no zoneamento final (ZIa e ZIb), bem como das duas zonas "mais 
quentes" deste (ZIIIb e ZIV). A partir disso, foi realizada uma análise da temperatura do ar, nos três horários de leitura diários para cada dia do mês representativo do verão (janeiro) e do inverno (julho) dos anos mais frio (2002) da série e do ano mais quente (2007).

A análise pode ser observada nos gráficos da Figura 4, que mostram os valores de temperatura do ar para a estação meteorológica de Iraí (representativa da zona IV), Campo Bom (representativa da zona IIIb), Bom Jesus (representativa da zona Ia) e Santa Vitória do Palmar (representativa da zona Ib) indicadas no mapa da Figura 3.

Pode-se observar que, nas estações meteorológicas representativas das zonas Ia e Ib (Bom Jesus e Santa Vitória do Palmar, respectivamente), a temperatura do ar, inclusive no mês de verão, apresenta-se com decréscimo, abaixo da zona de conforto (ZC), chegando próximo aos $13^{\circ} \mathrm{C}$, o que mostra que, do ponto de vista horário, mesmo no verão, há horas e, inclusive, dias em que a temperatura do ar para essas estações meteorológicas se apresenta tão baixa como em situações de inverno, como pode ser observado em comparação com a linha do inverno (azul).

Em compensação, analisando-se as estações meteorológicas representativas da zona IV e IIIb (Iraí e Campo Bom, respectivamente), nota-se que a temperatura do ar, mesmo nas situações de inverno, apresenta picos de acréscimo, os quais ultrapassam a zona de conforto (ZC), chegando, em alguns casos, aos valores dos $30^{\circ} \mathrm{C}$.

É possível observar também que, através dessa análise horária dos dias dos meses de verão e inverno para as estações meteorológicas representativas das zonas "mais quentes", há picos de temperatura que se aproximam e ultrapassam os $35^{\circ} \mathrm{C}$, em ambas as estações meteorológicas, o que representa, do ponto de vista do conforto térmico, situações de extremo desconforto por calor.

Foi proposta, então, uma regionalização climática do Rio Grande do Sul que abordasse esses extremos climáticos não observados, do ponto de vista de uma análise média dos atributos do clima. Elaborou-se o mapa da Figura 5, o qual aborda o método de extrapolação dos dados descrito na metodologia, e apresenta os mesmos valores de TEv e TR do zoneamento final. Tais valores foram distribuídos dentro do intervalo de classes que compreende as nove faixas de sensação térmica utilizadas nesta pesquisa. 

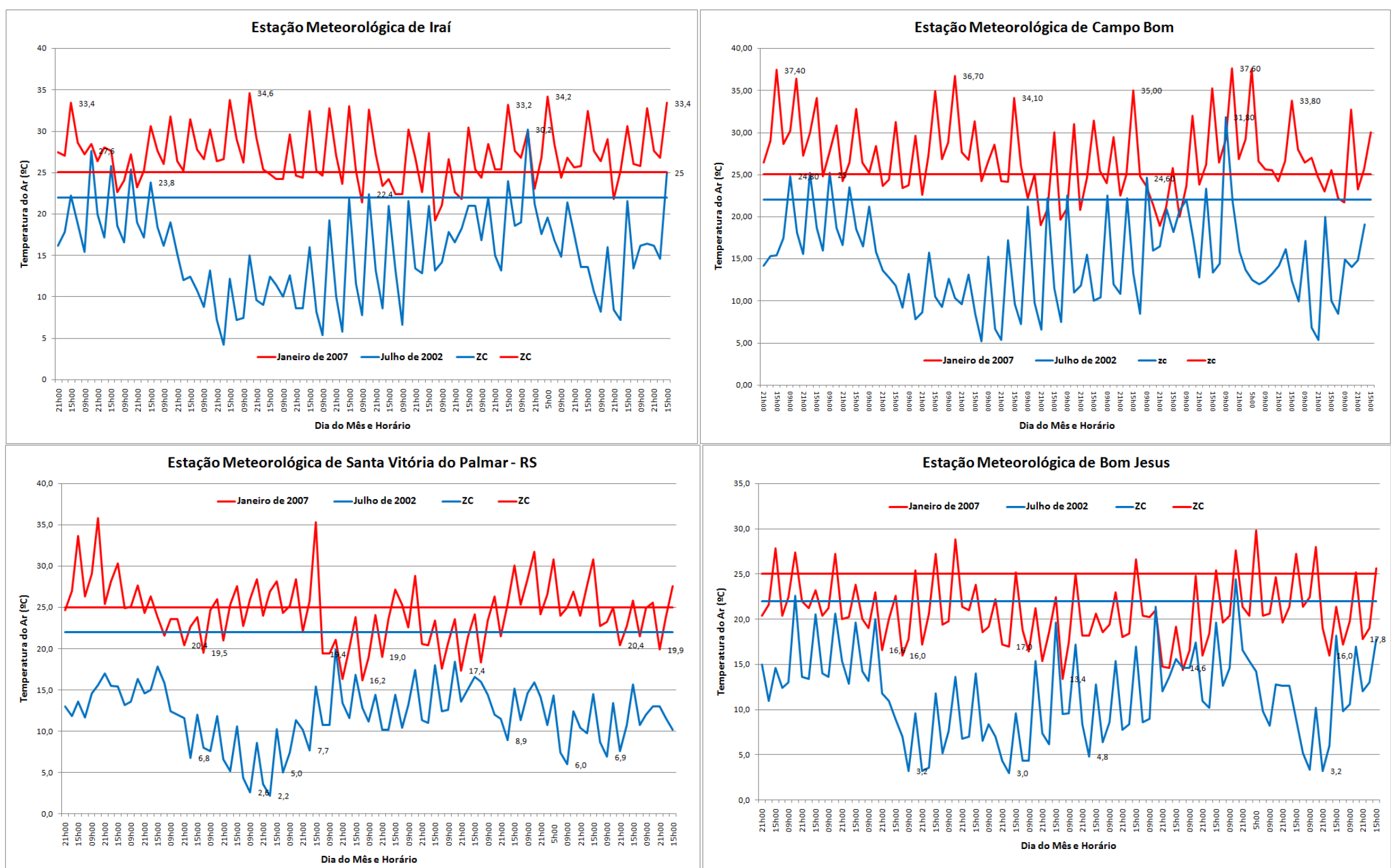

Figura 4: Análise horária/mensal da temperatura do ar para o mês representativo de verão do ano habitual (2007) e para o mês representativo de inverno do ano mais chuvoso (2002) das estações meteorológicas de Iraí, Campo Bom, Bom Jesus e Santa Vitória do Palmar (ZC = Zona de Conforto). Org. do Autor. 
Essa regionalização climática do conforto térmico humano parte do princípio observado na análise dos dados horários de temperatura do ar para as quatro estações meteorológicas representativas das zonas "mais frias" e "mais quentes" do zoneamento final. Nela se observa que, mesmo nas épocas mais quentes do ano (verão), nas estações localizadas nas zonas mais frias do Estado, há períodos horários e, inclusive, diários de temperaturas baixas, tal como em uma situação invernal.

Nas estações meteorológicas das zonas mais quentes do Estado, observa-se a tendência contrária: mesmo nas épocas mais frias do ano (inverno), há períodos de horas e até mesmo dias em que a temperatura se mantém elevada, tal como em uma situação de verão.

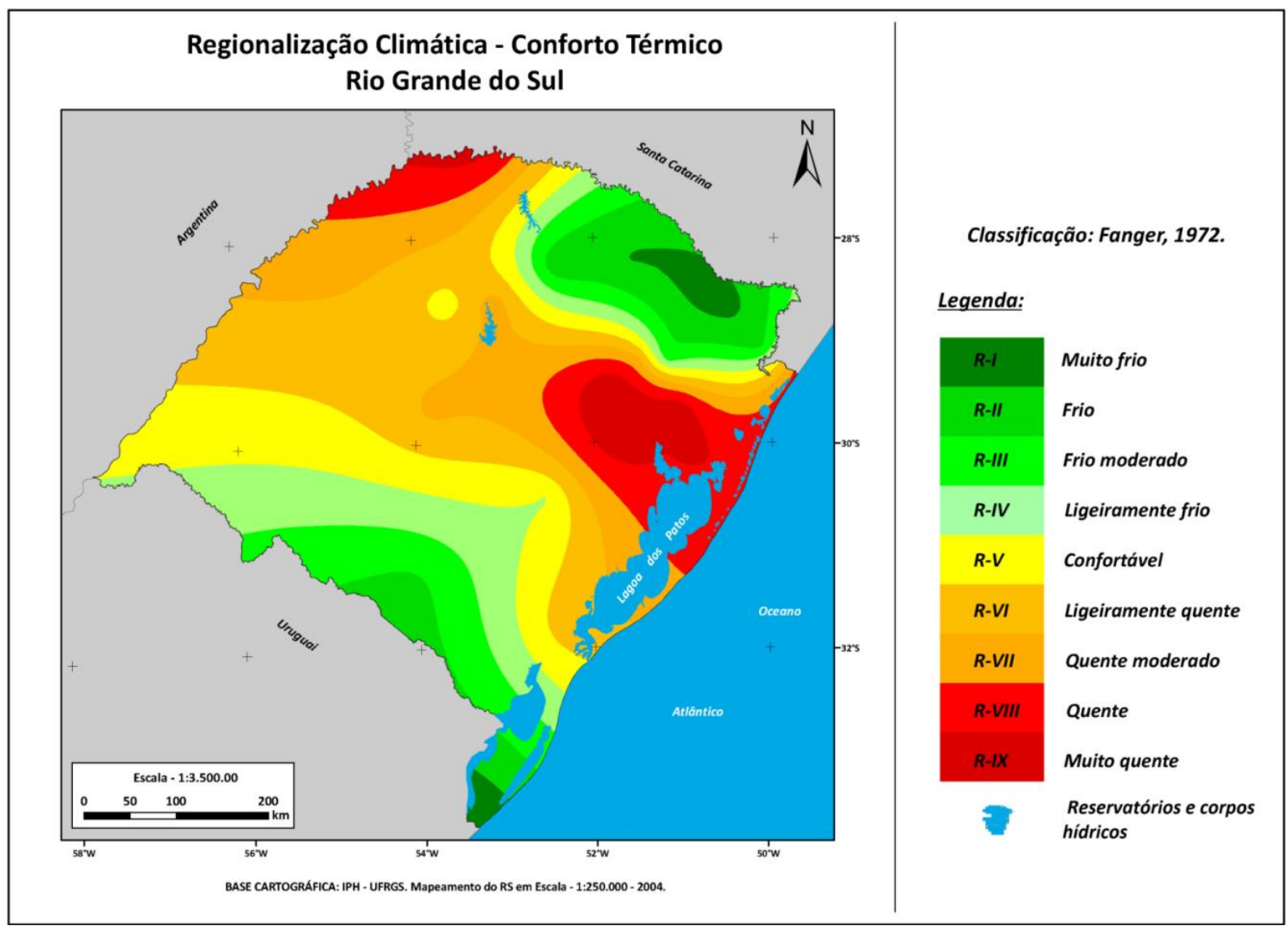

Figura 5: Mapa da regionalização climática do Rio Grande do Sul com base no zoneamento do conforto térmico humano. Org. do Autor.

Por fim, para uma análise mais sintetizada da regionalização climática do Rio Grande do Sul, com base no zoneamento do conforto térmico humano, foi proposto um mapa que resumisse a três as nove faixas de sensação térmica classificadas e regionalizadas no mapa da figura 5. Essas três gerariam um mapa das macrorregiões do conforto térmico humano no Estado (Figura 6). 


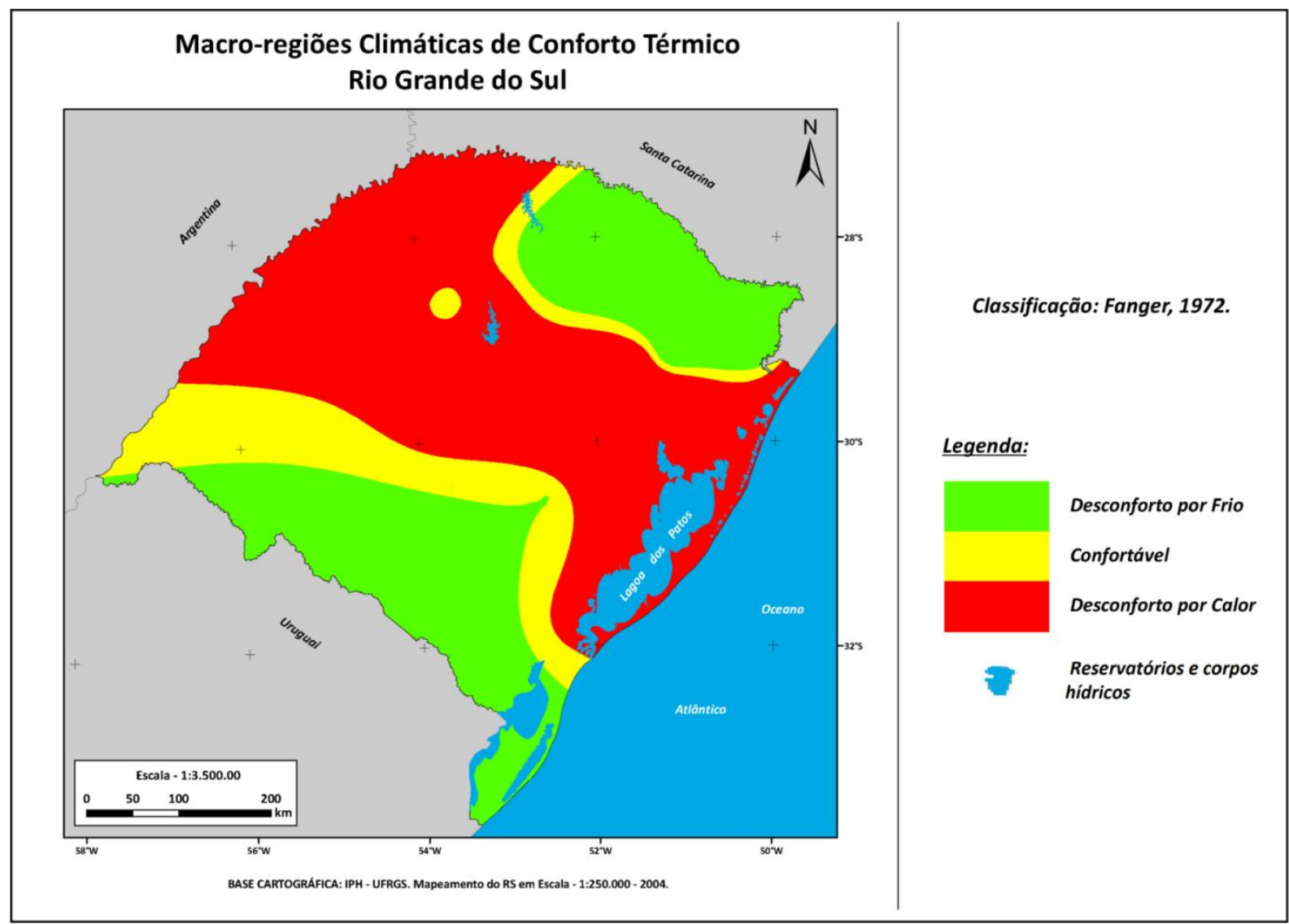

Figura 6: Mapa da macro-regionalização climática do Rio Grande do Sul com base no zoneamento do conforto térmico humano. Org. do Autor.

O mapa em questão divide o Rio Grande do sul em três regiões climáticas:

$\checkmark \quad$ Desconforto por Frio

Compreende as regiões nordeste, extremo sul e sudoeste do Rio Grande do Sul e classifica-se entre as faixas de sensação térmica de "Ligeiramente Frio" a "Muito Frio".

\section{$\checkmark \quad$ Confortável}

Revela-se como uma zona de transição entre a região de desconforto por frio e a de desconforto por calor, classificando-se na faixa de sensação térmica "Confortável".

\section{$\checkmark \quad$ Desconforto por Calor}

Compreende a faixa central do Estado, entre as duas regiões de conforto e as duas regiões de desconforto por frio, estendendo-se do litoral ao noroeste do Estado e classificando-se entre as faixas de sensação térmica de "Ligeiramente Quente" e "Muito Quente".

Essa macrorregionalização climática do conforto térmico no Rio Grande do Sul representa, de certa forma, um desvio padrão dos valores médios anuais das diferentes regiões climáticas do Estado, do ponto de vista do conforto térmico humano. Assim, generalizam-se as faixas de sensação térmica, a fim de melhor se representar a disposição geral das regiões. 


\section{CONSIDERAÇÕES FINAIS}

No zoneamento do conforto térmico para a série histórica de 30 anos (1981 2010), verificou-se a homogeneização das faixas de sensação térmica classificadas e mapeadas no território do Rio Grande do Sul, e a completa inserção do Estado nas faixas de sensação térmica abaixo da zona de conforto, com exceção dos casos de verão.

O Rio Grande do Sul, apresentou invernos e outonos frios, em função da influência determinante do vento no resfriamento dos resultados obtidos nos índices, o que fez com que os invernos do zoneamento da série de 30 anos fossem completamente representados por sensação térmica de "Muito Frio".

Quando realizado o zoneamento do conforto térmico final, observou-se que, apesar de o método adotado ter sido eficaz na distribuição das zonas de conforto térmico, no território do Rio Grande do Sul, o zoneamento não apresentou faixas de sensação térmica acima da zona de conforto nem a classificação destas, o que se mostrou distinto do que havia sido observado na análise da dinâmica atmosférica para os três anos-padrão.

Assim, através da análise horária da temperatura do ar para as estações meteorológicas representantes das zonas mais quentes e mais frias do zoneamento final, conseguiu-se propor uma regionalização climática que apresentasse os diferentes contrastes observados no Rio Grande do Sul, no decorrer das quatro estações do ano, sem que eles fossem subestimados pelos seus valores médios.

A regionalização climática do Rio Grande do Sul, com base no zoneamento do conforto térmico, mostrou-se eficaz ao conseguir expor, de maneira geral, não só as condições de conforto térmico predominantes nas mais distintas regiões do Estado assim como as

condições geográficas e climatológicas envolvidas na definição dessas regiões.

\section{AGRADECIMENTOS}

À Coordenação de Aperfeiçoamento de Pessoal de Nível Superior (CAPES) pela concessão de bolsa de estudo de mestrado.

\section{REFERÊNCIAS BIBLIOGRÁFICAS}

BERLATO, M.A; FONTANA, D.C. El Niño e La Niña: impactos no clima, na vegetação e na agricultura do Rio Grande do Sul: aplicações de previsões climáticas na agricultura. Porto Alegre: ed.da UFRGS, 2003.110p.

CHANGNON, S. A.; PIELKE JUNIOR, R. A.; CHANGNON, D.; SYLVES, R. T.; PULWARTY R.; Human Factors Explain the Increased Losses from Weather and Climate Extremes. Bulletin of the American Meteorological Society, Vol. 81, nr. 3, 437-442, 2000. 
COSTA, E. R. ; SARTORI, M. G. B ; FANTINI, V., Estudo da relação entre eventos El-Niño - La-Niña e ocorrência de ondas de frio na região de Santa MariaRS. Boletim Gaúcho de Geografia, v. 32-33, p. 263-276, 2008.

FANGER, P.O. Thermal comfort, analysis and application in environmental engineering. New York: McGraw Hill, 1972.

GOLDEN, J. S.; HARTZ, D.; BRAZEL, A.; LUBER, G.; PHELAN, P.; A biometeorology study of climate and heat-related morbidity in Phoenix from 2001 to 2006. International Journal of Biometeoroly, nr. 52, 471-480, 2008.

INSTITUTO BRASILEIRO DE GEOGRAFIA E ESTATÍSTICA. Ministério do Planejamento, Orçamento e Gestão. Coordenação de Agropecuária. Cidades. Rio de Janeiro: IBGE, 2014.

MAIA, J. A.; GONÇALVES, F. L. T. Uma análise do conforto térmico e suas relações meteorotrópicas na cidade de São Paulo - parte 1. Anais: XII Congresso Brasileiro de Meteorologia, p. 305-314, Foz de Iguaçu, 2002.

MATZARAKIS, A.; MAYER, H., Heat stress in Greece. International Journal Biometeoroly. 41:34-39, 1997.

MISSENARD, H. Equivalence Thermique dês Ambience. Chaleur et Industrie, 24; p.159-183. 1948.

MONTEIRO, C. A. F. O clima da região Sul. In: CATALDO, D. M. (Org.). Geografia do Brasil, Grande Região Sul. Rio de Janeiro: IBGE, p. 117-169, 1963.

MONTEIRO, C. A. F. A Frente Polar Atlântica e as Chuvas de Inverno na Fachada Sul-Oriental do Brasil (Contribuição metodológica à análise rítmica dos tipos de tempos no Brasil.) Série Teses e Monografias, nำ1. São Paulo: Instituto de Geografia/USP, 1969.

MONTEIRO, C. A. F. Análise rítmica em climatologia - problemas da atualidade climática em São Paulo e achegas para um programa de trabalho. Revista IGUSP. São Paulo. [s./v.], [s./n.], p. 1-21, 1971.

MONTEIRO, C. A. F. Teoria e Clima Urbano. São Paulo: Instituto de Geografia/USP, 181p. (Série Teses e Monografias, 25). 1976.

MONTEIRO, C. A. F. A dinâmica climática e as chuvas no estado de São Paulo. Rio Claro: UNESP- IGCE, 2000. CD-ROM.

MOURA, M. O.; ZANELLA, M. E., Escolha de “anos- padrão" para o estudo do conforto térmico em Fortaleza, CE: verificação de critérios. REVISTA GEONORTE, Edição Especial 2, V.1, N.5, p.547 - 560, 2012.

RIO GRANDE DO SUL. Secretaria da Coordenação e Planejamento. Atlas socioeconômico do Rio Grande do Sul. Porto Alegre: SCP, 2010. Impresso e on line, ed. atualizada. www.scp.rs.gov.br/atlas/

RUOSO, D.; SARTORI, M. G. B.; WOLLMANN, C. A.; COSTA, E. R. Respostas locais à circulação regional em Santa Maria e Santa Cruz do Sul: Uma análise de normais climatológicas de temperatura e precipitação. In: SIMPÓSIO BARSILEIRO DE CLIMATOLOGIA GEOGRÁFICA, 7. Rondonópolis: UFMT, 2006. 20-25 ago.Anais... 1CD-ROM. 
SARTORI, M. G. B., As variações pluviométricas e o regime das chuvas na região central do Rio Grande do Sul. Rio Claro, Boletim de Geografia Teorética, v. 23, p. 72-80, 1993.

SARTORI, M. G. B. A dinâmica do clima do Rio Grande do Sul: indução empírica e conhecimento científico. Revista Terra Livre, São Paulo, v. 1, no․ 20, p. 2749, jan./jul. 2003.

SECRETARIA ESTADUAL DO MEIO AMBIENTE. Governo do Estado do Rio Grande do Sul. Regiões Hidrográficas do Rio Grande do Sul. Disponível em: www.sema.rs.gov.br. Acesso em: 19 de fev. 2010.

SORRE, M. Le Climat. In: SORRE, M. Les Fondements de la Géographie Humaine. Paris: Armand Colin, 1951. Chap. 5, p.13-43

SUPING, Z.; GUANGLIN, M.; YANWEN, W.; JI, L. Study of the relationships between weather conditions and the marathon race, and of meteorotropic effects on distance runners. International Journal of Biometeorology, 36, 63-68, 1992.

WOLLMANN, C. A.; SARTORI, M. G. B., Frequência mensal e sazonal da participação de sistemas atmosféricos no verão do Rio Grande do Sul: análise sobre três casos típicos (1986/1987, 1997/1998 e 2004/2005). Ciência e Natura, UFSM, 31 (1): $141-161,2009$. 